ANNUAL TECHNICAL REPORT

for

\title{
GEOSCIENCE/ENGINEERING CHARACTERIZATION OF THE INTERWELL ENVIRONMENT IN CARBONATE RESERVOIRS BASED ON OUTCROP \\ ANALOGS, PERMIAN BASIN, WEST TEXAS AND NEW MEXICO
}

Contract No. DE-AC22-93BC14895

\author{
Prepared by \\ Bureau of Economic Geology \\ The University of Texas at Austin
}

F. J. Lucia, Co-Principal Investigator

C. Kerans, Co-Principal Investigator

Reporting Period: September 29, 1995 - September 28, 1996 
ANNUAL TECHNICAL REPORT

for

\begin{abstract}
GEOSCIENCE/ENGINEERING CHARACTERIZATION OF THE INTERWELL ENVIRONMENT IN CARBONATE RESERVOIRS BASED ON OUTCROP ANALOGS, PERMIAN BASIN, WEST TEXAS AND NEW MEXICO
\end{abstract}

Contract No. DE-AC22-93BC14895

\begin{abstract}
OBJECTIVE
The objective of this project is to investigate styles of reservoir heterogeneity found in low permeability pelleted wackestone/packstone facies and mixed carbonate/clasticfacies found in Permian Basin reservoirs by studying similar facies exposed in the Guadalupe Mountains. Specific objectives for the outcrop study include construction of a stratigraphic framework, petrophysical quantification of the framework, and testing the outcrop reservoir model for effects of reservoir heterogeneity on production performance. Specific objectives for the subsurface study parallel objectives for the outcrop study.
\end{abstract}

\title{
SUMMARY OF TECHNICAL PROGRESS
}

Field work has been completed and a three dimensional model has been constructed for a 40-acre area in the northeast section of south Cowden field. The petrophysical properties in the model are intended to specifically represent the tract 20 area of the Moss unit. The well arrangement represents an injection pattern similar to that historically applied in the area: a line drive with two injectors on the west edge and three producers on the east. This well arrangement approximately matches the average number of injectors per section (eight) and the average injector-producer ratio (1:2) in sections 5, 6, 7, and 8.

Preparation of two final reports that summarize research results of the South Cowden field has been initiated. One report summarizes results of the petrophysical characterization research, and one summarizes results of the fluid-flow modeling research. 
We are also preparing the final report, which summarizes the research results of the Grayburg outcrop reservoir study. Additional samples for porosity and permeability were taken along a horizontal traverse in a canyon parallel to the orginal horizontal traverse. These data will be used to further evaluate the spatial statistics of permeability variability in carbonate reservoirs. 